\title{
Correlation between the arsenic concentrations in the air and the SMR of lung cancer
}

\author{
Masaharu Yoshikawa $\cdot$ Kazuo Aoki $\cdot$ \\ Naoyuki Ebine · Masahiro Kusunoki • \\ Akihiro Okamoto
}

Received: 4 October 2007/ Accepted: 3 March 2008/Published online: 26 April 2008

(C) The Japanese Society for Hygiene 2008

\begin{abstract}
Objectives To verify whether the concentrations of arsenic (As) and its compounds in the air (referred to here as arsenic concentrations) affect the standardized mortality ratio (SMR) associated with lung cancer.

Methods Using monitoring survey data on arsenic concentrations published by the Ministry of the Environment, we classified the municipalities for which arsenic concentrations were measured (measured municipalities) into ten groups according to the average arsenic concentration. We then determined the SMR of lung cancer, stomach cancer, pneumonia, cerebrovascular disease and cardiac disease for each group using socio-demographic data, such as the national census and demographic trends. The relationships between these factors were compared and investigated by statistical means.

Results No effect of arsenic concentrations on stomach cancer, cerebrovascular disease or cardiac disease was observed, and while significant differences in pneumonia were observed among several of the male subjects, there were no significant effects of arsenic concentration. However, lung cancer and arsenic concentration showed a significantly positive correlation for both males and
\end{abstract}

M. Yoshikawa $\cdot$ K. Aoki $\cdot$ N. Ebine $\cdot$ M. Kusunoki ·

A. Okamoto

Division of Preventive Medicine, Department of Human

Environmental and Social Medicine, Oita University

Faculty of Medicine, Yufu, Oita 879-5593, Japan

Present Address:

K. Aoki ( $\square)$

Division of Environmental and Preventive Medicine, Department of Social and Environmental Medicine, University of the Ryukyus, Faculty of Medicine, 207 Uehara, Nishihara-cho, Okinawa 903-0215, Japan e-mail: aoki-k@med.u-ryukyu.ac.jp females (males: Spearman $r=0.709, P<0.05$; females: Spearman $r=0.758, P<0.05$ ). The probability of type $\alpha$ error was less than $5 \%$ in areas with more than $1.77 \mathrm{ng} \mathrm{As} /$ $\mathrm{m}^{3}$ (71st percentile) and less than $1 \%$ in areas with more than $2.70 \mathrm{ng} \mathrm{As} / \mathrm{m}^{3}$ (91st percentile). These results confirm that the SMR of lung cancer tends to be higher than the national average in areas of higher arsenic concentrations. Conclusions The SMR of lung cancer is significantly higher in areas with arsenic concentrations of $1.77 \mathrm{ng} / \mathrm{m}^{3}$ or more.

Keywords Air pollutant - Arsenic - Lung cancer . Municipal tobacco tax income .

Standardized mortality ratio

\section{Introduction}

Arsenic (As) concentrations in the atmosphere are known to be high in Saganoseki-cho (now Saganoseki district, Oita City, due to a municipal merger) in Oita Prefecture, where a copper smelter is located. To safeguard the health of the town's residents, since 1974 Oita Prefecture Agency has regularly measured the level of arsenic from a monitoring site located on the roof of Town Hall of Saganosekicho [1]. Smelters of nonferrous metals, such as copper and zinc, are scattered throughout Japan, and it is known that arsenic concentrations tend to be high in areas neighboring such industries [2]. At a meeting of the Public Health Association that was open to the general public, speakers involved in public health in Oita Prefecture reported that the mortality rate of the town's residents due to lung cancer was higher than the average of Oita prefecture.

The Air Pollution Control Law was partially amended in May 1996, and one of the major amendments was in the area 
of health-related countermeasures against long-term exposure to low concentrations of hazardous air pollutants. In a report by the Central Environment Council made in October 1996, following implementation of the amendments, arsenic was selected as one of 22 substances that are to be regarded as hazardous air pollutants associated with high health risks. The report also recommended that immediate action be taken to ensure that arsenic levels remain at acceptable levels. Arsenic has been classified as a group 1 carcinogen by the World Health Organization's (WHO) International Agency for Research on Cancer [3]. The standard value of arsenic is $0.002 \mu \mathrm{g} / \mathrm{m}^{3}$, which is equivalent to a $10^{-5}$ risk level of the unit risk set by the US Environmental Protection Agency, whose values are considered to be equal to the standard environmental values used in Japan. The guidelines established by the WHO's European Regional Office has set the value at $0.0067 \mu \mathrm{g} / \mathrm{m}^{3}$ [4].

Few reports are available on the effect of arsenic concentrations on the human body, especially regarding malignant neoplasms of the trachea, bronchus and lung (lung cancer). However, numerous studies have described the arsenic content in foods and drinking water [5-8], and data in reports on arsenic in the working environment indicate that the carcinogenic risk among workers increases in the presence of more than $54.6 \mu \mathrm{g} / \mathrm{m}^{3}$ of arsenic in the atmosphere [9]. This value attracted our attention as it emphasizes that there are significant differences in the concentrations of arsenic that are considered to have an effect on human health in the working environment and those embedded in environmental standards. In addition, the causal relation between smoking and lung cancer has almost been established by many groups of researchers [10-15], and smoking is the immediate causal factor in $70 \%$ of all lung cancers for men [16].

The aim of this study was to verify whether the arsenic concentrations truly influenced the incidence and mortality of patients with lung cancer by performing a statistical analysis using mainly statistical data. To examine the smoking confounders causing lung cancer, we added four diseases as targets: cerebrovascular disease and heart disease (two of the three major causes of death in Japan); stomach cancer (cancer); pneumonia (noncancerous respiratory diseases).

\section{Materials and methods}

Data

The statistical data used were obtained from: (1) the monitoring of hazardous air pollutants [17], (2) national health maps maintained by the municipality [18], (3) health and welfare statistics [19], (4) national census results [20],
(5) monthly and annual data on environmental air values [21] and (6) municipal settlement situation surveys [22].

Overview of the hazardous air pollutants survey

The survey was conducted by each local public authority according to both the guidelines and the manual for measurement methods established by the Ministry of the Environment, and the methods for collecting and analyzing samples were consistent among municipalities. As a rule, suspended solids in the atmosphere were collected as samples using an high volume air sampler at least once a month at the same measurement point with due consideration of seasonal changes, diffusion, wind direction and other factors, and the level of arsenic was quantitatively determined using a mass spectrometry method after appropriate sample preparation, such as acid treatment. The published data include the names of each measurement point, number of samples, average values and range from minimum to maximum at each measurement point for each year and each of the municipalities carrying out measurements.

The definition of a measured municipality is a municipality in which the prefecture had conducted surveys for 5 consecutive years (1999-2003) by placing monitoring/ measurement stations at one or more locations in that municipality (representative locations, locations in close proximity to a factory and areas along roads). In total, there were 388 measurement locations/monitoring stations in 264 measured municipalities.

\section{Summarizing and grouping of arsenic concentrations}

Based on the data obtained from source (1), we calculated the average value from FY1999 to FY2003 per measured municipality for the 264 measured municipalities throughout the country where arsenic concentrations were measured. The measured municipalities were then ranked in increasing order of average arsenic concentrations and subsequently classified into ten groups for every ten percentile (see Table 1).

\section{Summarizing and analyzing SMRs}

To assess mortalities in the observed groups (ten percentile groups) associated with lung cancer, stomach cancer, cerebrovascular disease and cardiac disease, we first summarized and then used the latest data obtained from (2) and the data on pneumonia from (3) for the 5 years from FY (fiscal year) 1995 to FY 1999. For mortalities of the standard group (nationwide), we summarized and then used mortalities classified by age into 5-year groups for (3) in the same year. For the population of the standard group and 


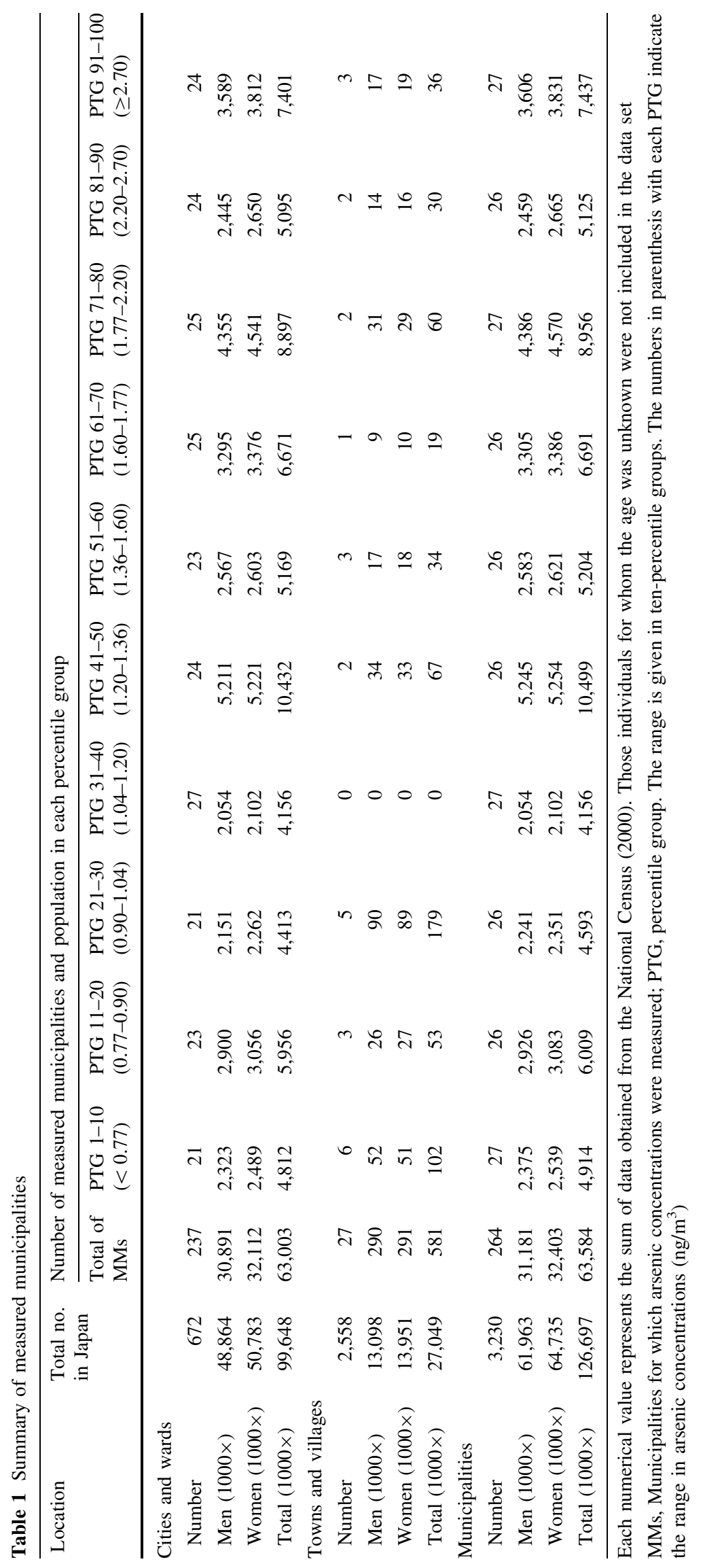


the observation groups, the population was classified by age into 5-year groups according to (4) in 1995 and 2000.

The respective SMRs were derived by the difference from actual mortalities after expected mortalities of the observation groups were calculated by means of proportional calculations [23], and the correlation between arsenic concentrations and SMRs of lung cancer, stomach cancer, pneumonia, cerebrovascular disease and cardiac disease were statistically analyzed.

Interannual change in arsenic concentrations (assessment of latency period)

Because the monitoring of hazardous air pollutants (1) began in FY 1997, it was necessary to determine the difference from earlier arsenic concentrations levels and to consider a latency period for the carcinogenesis caused by arsenic concentrations. A bibliographical survey was conducted to encompass prefectures that had conducted arsenic surveys in the late Showa Era. We found that iron, manganese, vanadium and other elements in the atmosphere had been measured by ten prefectures during this period but that atmospheric arsenic concentrations had been analyzed by only three prefectures: Aomori, Shiga and Oita. One of the reasons why arsenic was not monitored so widely is probably linked to the analytic approach necessary: arsenic concentrations are determined by atomic absorption spectrometry for which a reduction-vaporization method must be used; as such, arsenic can not be analyzed together with other metals. In Aomori Prefecture, we were able to obtain data from Aomori City [24, 25], in Shiga Prefecture, we obtained data from Otsu City, Nagahama City, Youkaichi City and Imazucho [26, 27], and in Oita Prefecture, we obtained data from Oita City [28] and Saganoseki-cho [1].

\section{Correlation between air-polluting substances}

and arsenic concentrations

Because the air-polluting substances include sulfur dioxide $\left(\mathrm{SO}_{2}\right)$, nitrogen dioxide $\left(\mathrm{NO}_{2}\right)$, suspended particulate matter (SPM), carbon monoxide (CO), among others, for which environmental quality standards have been set [29], we checked whether the presence of air-polluting substances (confounders) affected the relationship between arsenic concentrations and the SMRs of lung cancer, stomach cancer, pneumonia, cerebrovascular disease and cardiac disease. Therefore, the data for three air-polluting substances- $\mathrm{SO}_{2}$, a known causative substance of asthma, and $\mathrm{NO}_{2}$ and SPM, which have recently received a great deal of attention due to their high concentrations in car exhaust emissions [30]—-were used as representative indices and summarized for each ten-percentile group using the data of (5) from FY 1999 to FY 2003. The results were analyzed statistically using the Kruskal-Wallis test and the Scheffe test. In addition, to determine the interannual change in arsenic concentrations and the concentrations of air-polluting substances, we collected nationwide average data on $\mathrm{SO}_{2}, \mathrm{NO}_{2}$ and SPM from the late Showa Era to the most recent period [31].

\section{Effect of smoking on lung cancer}

The effect of smoking on lung cancer has been particularly well documented $[14,15]$. Therefore, using data on the "municipal tobacco tax income" obtained from source (6) from FY 1999 to FY 2003, we obtained the annual tobacco tax income amount per adult (tobacco consumption) in the measured municipalities. A statistical analysis was performed using the Kruskal-Wallis test between each tenpercentile group to investigate these effects. In addition, the tobacco tax is a local tax that is imposed on tobacco consumption, and when a tobacco maker sells tobacco to a retailer, the retailer has to pay the tobacco tax to the municipality in which they are located. The tax rate as of 1998 was 2,434 yen per 1,000 cigarettes that were sold to retailers. To the best of our knowledge, we are the first to have used the total taxed amount divided by the number of adults in each ten-percentile group as indicators of the amount of tobacco consumed by each target group.

\section{Analysis}

The difference in the respective SMRs was evaluated, assuming a Poisson distribution as established by Furukawa and Tango [32]. The estimate of each SMR confidence interval in each percentile group was based on "analyses essential for epidemiology" by Nakamura [33, 34]. For the correlation between SMRs of each disease and arsenic in each percentile group, we used the Spearman rank correlation coefficient of a nonparametric indicator, as the SMR showed a Poisson distribution. In the test for differences between air-polluting substances, such as each $\mathrm{SO}_{2}$ concentration in each percentile group, we used the KruskalWallis test, which is a nonparametric test. In addition, when a significant difference was observed between groups, the presence or absence of each significant difference was verified using the Scheffe analysis as a post hoc comparison. The Kruskal-Wallis test was used to test the differences in the taxed amount of tobacco per adult in each percentile group. Pearson's product-moment correlation coefficient $(r)$ was used to study the relationship between the average value of arsenic concentrations and the average value of air-polluting substances in each percentile group. In the test for differences between males and females in the SMR of each disease, we used the paired $t$ test. 


\section{Results}

\section{Arsenic concentrations}

A summary of the municipalities with high and low arsenic concentrations is shown in Table 1. The maximum average value of arsenic concentrations for the 5-year study period was $24.9 \mathrm{ng} / \mathrm{m}^{3}$ in Saganoseki-cho; the minimum average value was of $0.36 \mathrm{ng} / \mathrm{m}^{3}$, in Obihiro. The average arsenic concentration ( \pm standard deviation) for the 5-year period was $1.71 \pm 1.75 \mathrm{ng} / \mathrm{m}^{3}$. In addition to Saganoseki-cho, most of the municipalities which have nonferrous metal smelters located within their boundaries, such as Takehara $\left(8.15 \mathrm{ng} / \mathrm{m}^{3}\right)$, Naoshima-cho (7.92 ng/ $\left.\mathrm{m}^{3}\right)$, Hachinohe $\left(5.09 \mathrm{ng} / \mathrm{m}^{3}\right)$, Tamano $\left(4.10 \mathrm{ng} / \mathrm{m}^{3}\right)$ and Niihama $\left(3.40 \mathrm{ng} / \mathrm{m}^{3}\right)$, also belonged to the percentile group 91-100, as did Kitakyushu $\left(3.24 \mathrm{ng} / \mathrm{m}^{3}\right)$, Osaka $\left(3.13 \mathrm{ng} / \mathrm{m}^{3}\right)$ and Yokkaichi $\left(3.05 \mathrm{ng} / \mathrm{m}^{3}\right)$, each of which has industrial areas.

Interannual change of arsenic concentrations

The interannual change in the average arsenic concentrations, averaged for 5-year periods, was assessed in seven cities and towns of three prefectures that had longterms data on arsenic concentrations (Table 2). This information was then considered in terms of the latency period for carcinogenesis associated with atmospheric arsenic levels. The national average concentrations of $\mathrm{SO}_{2}, \mathrm{NO}_{2}$ and SPM during the same periods are also given in Table 2.

Correlation between the state of air pollution and arsenic concentrations

The average concentration of $\mathrm{SO}_{2}, \mathrm{NO}_{2}$, and $\mathrm{SPM}$ for each ten-percentile group is given in Table 3. For the $\mathrm{NO}_{2}$ concentration, there was no significant difference between the ten-percentile groups, as determined by the KruskalWallis analysis of variance $(P=0.153)$. However, there was a significant difference in the $\mathrm{SO}_{2}$ and SPM concentrations $\left(\mathrm{SO}_{2}: P=0.042\right.$; SPM: $\left.P=0.038\right)$ and, therefore, the Scheffe test was conducted. However, there was no significant difference for either $\mathrm{SO}_{2}$ or SPM between the individual percentile groups.

Smoking situation for each percentile group

A summary of the municipal tobacco tax income per adult in the measured municipalities comprising each percentile group is given in Table 3. No significant difference was observed between the groups using the Kruskal-Wallis analysis of variance $(P=0.120)$.
Correlation between arsenic concentrations and air-polluting substances

A highly significant statistically positive correlation was observed for the air-polluting substances studied between the average value of arsenic concentrations data and the average value of $\mathrm{SO}_{2}$ data in each percentile group. Pearson's product-moment correlation coefficient $(r)$ and the corresponding $P$ values for this correlation were $r=0.810$ and $P=0.005$, respectively. No significant statistical correlation was observed between the average value of the arsenic concentrations and the average value of the $\mathrm{NO}_{2}$ and SPM data in each percentile group $\left(\mathrm{NO}_{2}\right.$ data: $r=-0.074$, NS; SPM data: $r=0.519$, NS).

Results of an analysis of SMRs

The SMRs of lung cancer, stomach cancer, pneumonia, cerebrovascular disease and cardiac disease for each of the ten-percentile groups are given in Table 4. The Spearman rank correlation coefficient did not reveal any correlation between arsenic concentrations and the respective SMRs of stomach cancer, cerebrovascular disease and cardiac disease in males and females $(P<0.05)$. Pneumonia showed a significantly positive correlation in male subjects in the Spearman rank correlation coefficient (Spearman $r=0.891, P<0.001$ ), and the SMR was significantly high (showing percentile group 91-100), but the other groups did not show significantly high values. In contrast with men, there were no significant correlations in women (Spearman $r=0.515$, NS). The SMR was significantly high, showing percentile group 41-50, but there were no significant differences in the high percentile groups.

However, lung cancer had a significantly positive correlation for both women and men (men: Spearman $r=0.709, \quad P<0.05$; women: Spearman $r=0.758$, $P<0.05)$, and the probability of type $\alpha$ error was less than $5 \%$ in areas with more than $1.77 \mathrm{ng} / \mathrm{m}^{3}$ (71st percentile) of arsenic concentrations and less than $1 \%$ in areas with more than $2.70 \mathrm{ng} / \mathrm{m}^{3}$ (91st percentile). This result confirms that the SMR of lung cancer tends to be higher than the national average (see Fig. 1).

\section{Discussion}

To verify whether arsenic affects the incidence of various diseases, it is importance of consider the validity of the latency period and the spatial representability of the measurement points of arsenic concentration. In terms of the validity of the latency period, the ideal approach would be to observe the effect of arsenic concentrations on the 


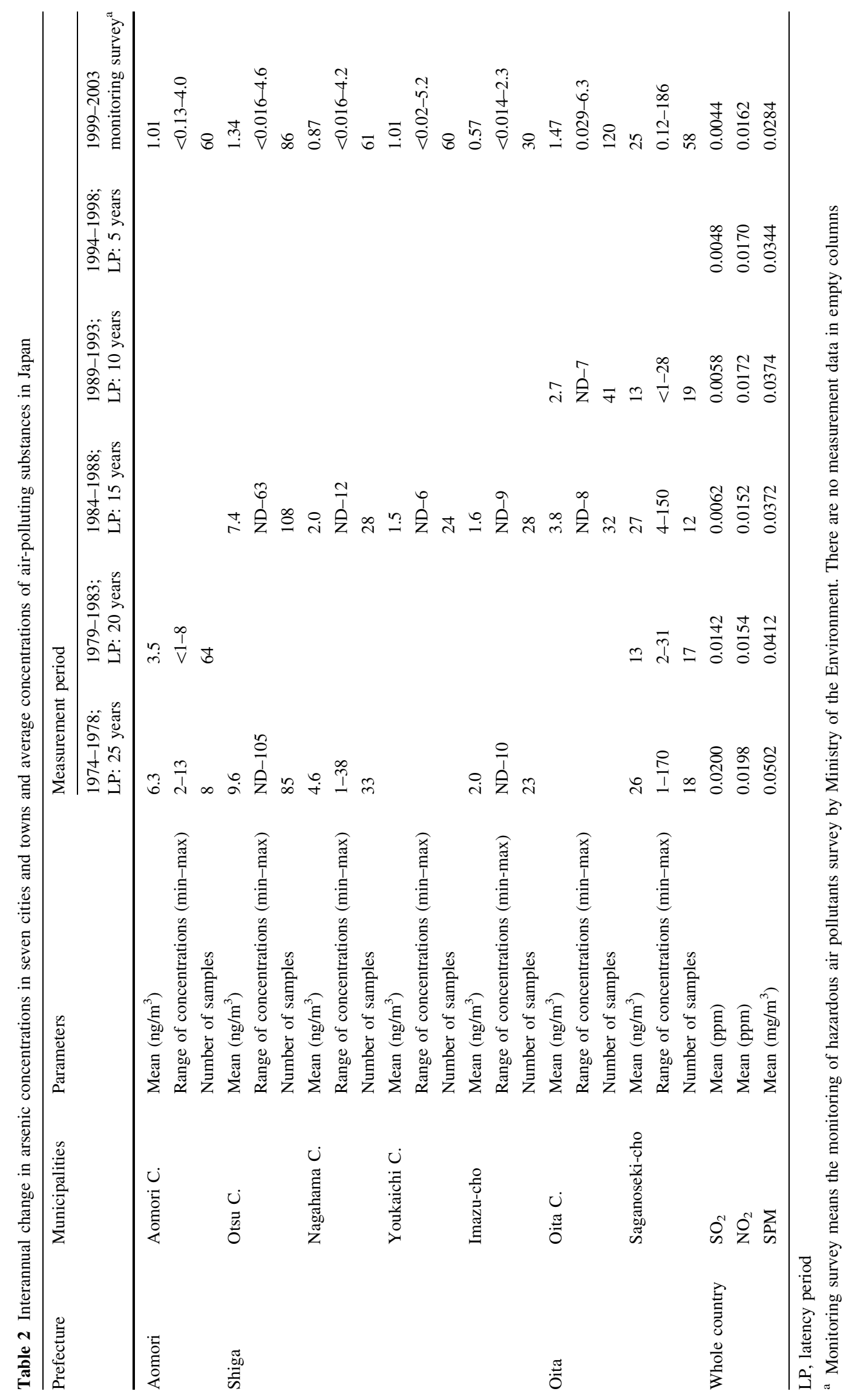




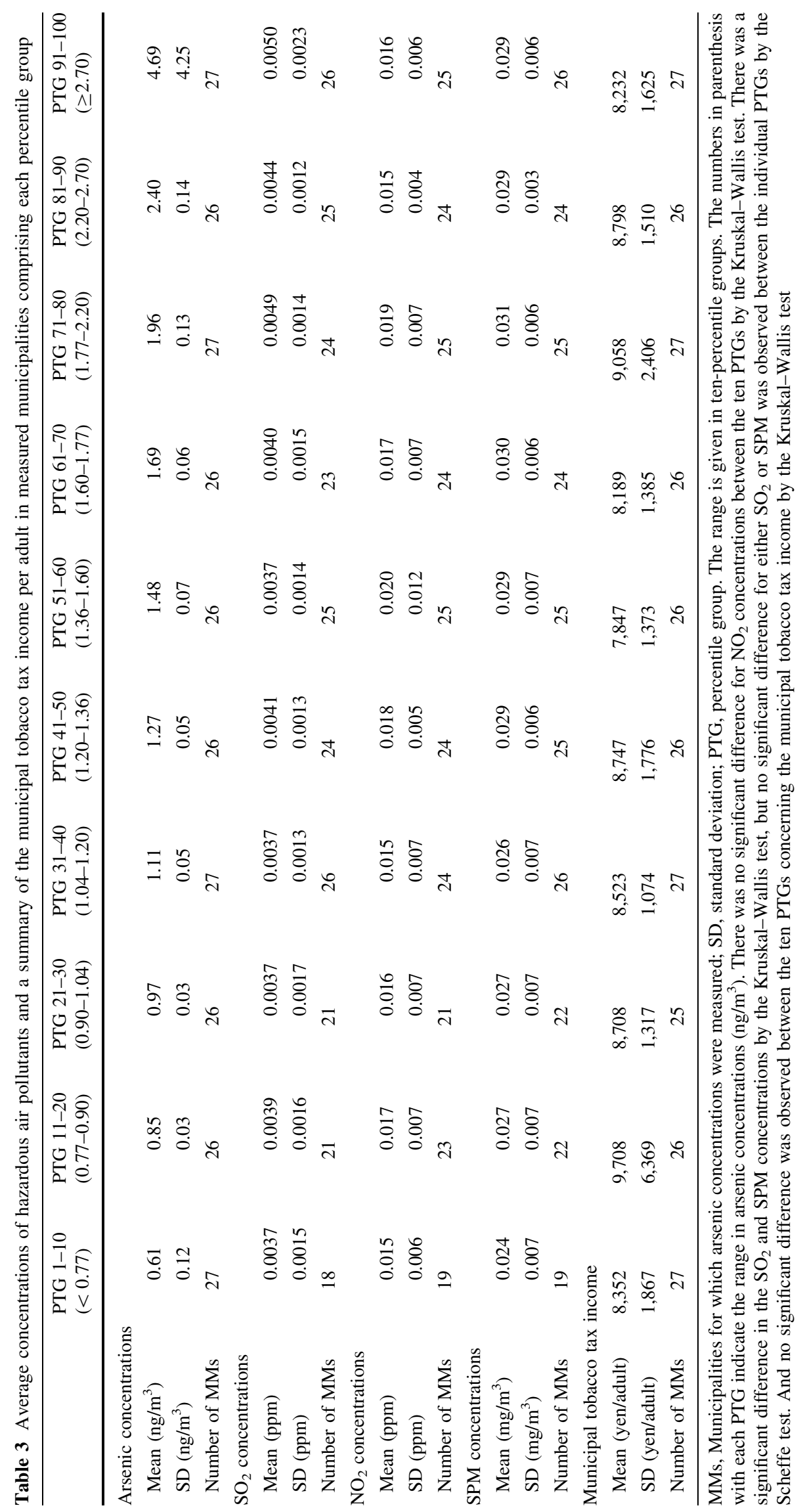




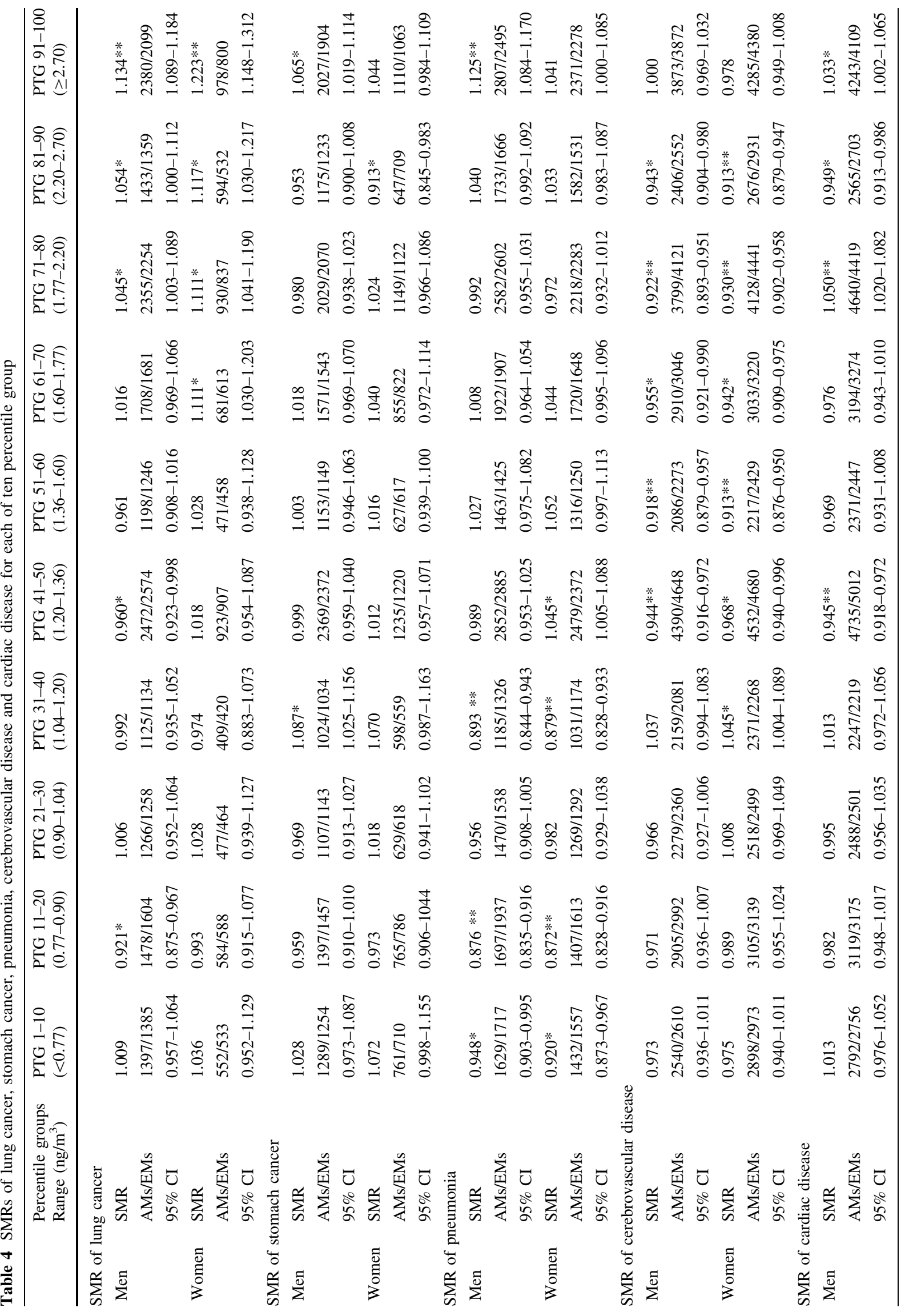




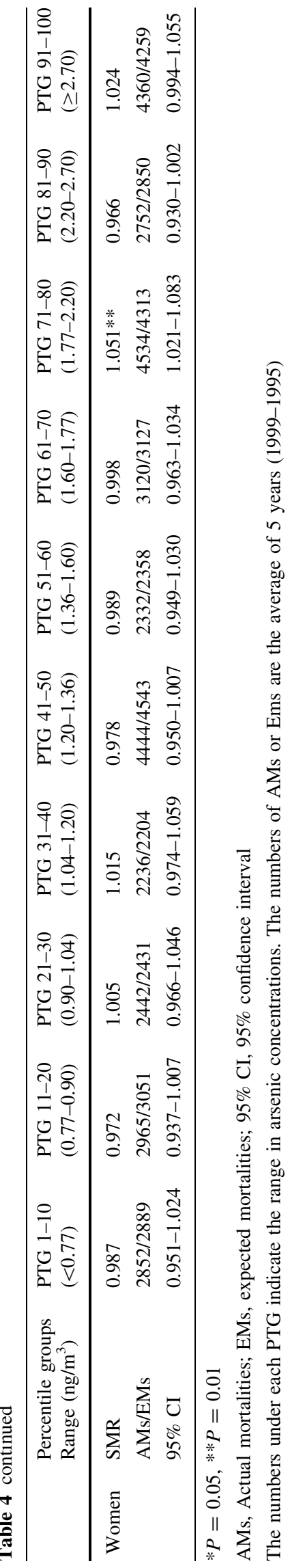

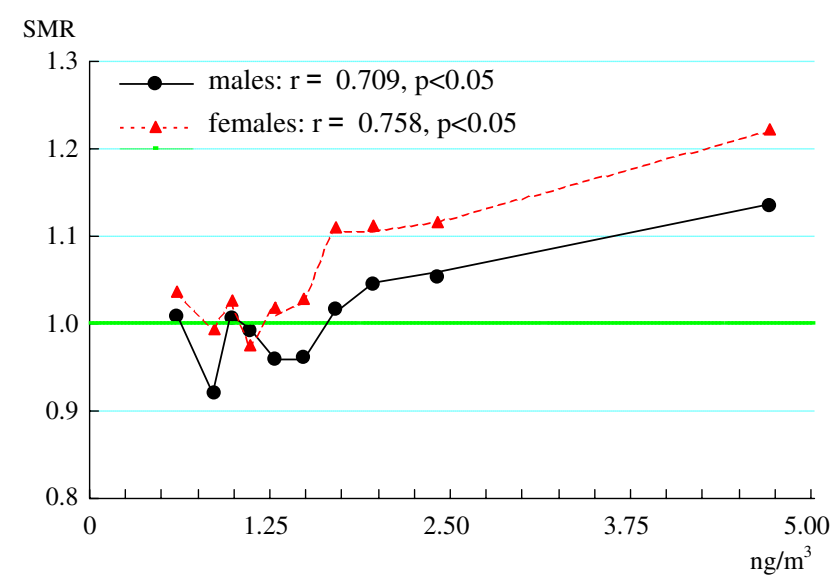

Fig. 1 The standardized mortality ratios (SMRs) of lung cancer for each ten-percentile group. The SMRs are plotted at the position of the mean concentration of each percentile group

respective SMRs over the long term; however, we had only limited statistical data. Based on the Pearson's productmoment correlation coefficient (Table 3), we found a highly significant statistically positive correlation between the arsenic concentration and the $\mathrm{SO}_{2}$ concentration data in each percentile group. Because most atmospheric $\mathrm{SO}_{2}$ originates from activities associated with industry, such as exhaust emissions from factories, we hypothesize that the characteristics of arsenic concentrations are similar those of $\mathrm{SO}_{2}$. A weak correlation was observed between the arsenic concentrations and the SPM concentrations, while very little correlation was observed between the former and the $\mathrm{NO}_{2}$ concentrations. Therefore, we infer that car exhaust emissions and not industrial activities influence both $\mathrm{NO}_{2}$ and SPM concentrations.

Following implementation of the Environmental Pollution Diet Session in 1970, antipollution measures began to be established across Japan, and from 1985 to 1988 (the 60 s of Showa Era), there was overall progress in the environmental policy, the adoption of advanced pollution prevention technology by companies and efforts toward conserving resources and energy [35]. Based on reports that describe how industrial pollution has been reduced, it is highly unlikely that the situation across the country between 1999 and 2003 was worse than that in the late Showa Era. Table 2 provides data on this situation; in particular, it can be seen that the $\mathrm{SO}_{2}$ and SPM concentrations for the whole country have been gradually decreasing in each 5-year period. The arsenic concentrations showed the same tendency in the six cities and towns of this study, with the exception of Saganoseki-cho, which showed a leveling-off tendency. As described above, although we cannot be certain based on data obtained from only seven cities and towns in three prefectures, we conclude that the residents in measured municipalities had 
been exposed to arsenic for long periods of time at certain concentrations and that these concentrations have decreased sequentially over the years. In other words, the arsenic concentrations have gradually stabilized during the 5-year period from FY 1999 to FY 2003.

In terms of the spatial representability of the measurement points, among the measured municipalities, 66 measured municipalities had multiple measurement points, while the remaining 198 measured municipalities had only one measurement location/station each. However, because most of the 198 measured municipalities used public facilities as their measurement points, mostly located in the centers of the measured municipalities, and measured the arsenic concentration levels at least once a month while taking seasonal variations, wind direction, and other factors into consideration, they can be considered to be representative of residents' exposure to arsenic, although still technicall insufficient.

The effect of smoking is a key confounder, particularly for lung cancer. An appropriate technique for assessing this confounder was unavailable at the time of the study, though we searched for an analytical technique that would assume smoking to be an adjustment variable. While searching, we used the tobacco tax to verify the smoking confounder. In an ecological study, it is believed that the effect from potential confounders, such as smoking, cannot be adjusted sufficiently. Therefore, the analysis we conducted was not to demonstrate that smoking did not act as the confounder, but rather to verify whether there were differences in each percentile group, with the assumption that smoking has already had an effect on each percentile group. Based of the findings of the Kruskal-Wallis test there were no significant differences with regard to tobacco taxes in each percentile group; therefore, it may seem that the amount of tobacco consumption affected each group at the same intensity. However, the following limitations are associated with the tobacco tax as employed in our study: (1) it is not sufficient as a confounder to presume that smoking influences each individual; (2) in terms of the influence on the group, the statistical data related to the tobacco tax are not effective factors for many smoking confounder indices to clarify the smoking influence. We recognize that it is necessary to pay scrupulous attention to the evaluation of smoking confounders when the tobacco tax is used as a confounding factor. Therefore, we have no intention of concluding that the confounding effect of smoking can be completely excluded in a statistical analysis using the tobacco tax that we employed. As for the relationship between smoking and lung cancer, we are considering pursuing further studies as an important part of our future agenda, based on the synergistic effects of arsenic exposure and smoking as well as other ecological perspectives.
Based on the results presented here, which show no correlation between arsenic concentrations and the SMRs of men and women for stomach cancer, cerebrovascular disease and cardiac disease, we suggest that arsenic is not linked to the appearance of these diseases. In terms of the SMR of pneumonia, no significant differences in arsenic levels were observed for female subjects, but the results showed a higher probability for male subjects. However, only groups with percentile group 91-100 showed significant differences in the SMRs. It is conceivable that this resulted from the working environment of male factory workers because most groups with percentile group 91-100 comprised of subjects who lived in cities close to or encompassing industrial areas. Moreover, no significant differences were observed between female subjects, thereby supporting our suggestion that arsenic had no effect on the appearance of pneumonia.

For the SMR of lung cancer, we observed a strongly positive correlation for both males and females (particularly noteworthy in percentile groups with high arsenic concentrations) as well as significant difference from high percentile groups (see Fig. 1). It can therefore be presumed that arsenic concentrations may have certain effects on the appearance of lung cancer. However, no correlation was found for either men or women in the groups of less than 51st percentile (men: Spearman $r=-0.4$, NS; women: Spearman $r=-0.5$, NS) on Fig. 1. This result is believed to originate from the fact that the SMR of lung cancer is strongly affected if arsenic concentrations are observed to exceed a certain level.

In terms of the paired $t$ test, no significant differences in the respective SMRs between women and men were observed for stomach cancer, pneumonia, cerebrovascular disease or cardiac disease. However, lung cancer did show a significant difference and tended to be higher among females $(P<0.001)$; this was particularly noticeable in percentile groups with high arsenic concentrations (the groups of more than 51st percentile: $P<0.001)$. The causes for this development are based on numbers; the "smoking population in 1999 was estimated to be $33,630,000$, including 26,420,000 males and 7,210,000 females, and about eight of ten smokers were male" [36]. Therefore, one of the causes of this result may be that the amount of tobacco tax that we used for verifying the smoking confounder was to determine the differences in the amount of tobacco consumption per adult and, therefore, the differences between males and females were not predicted. However, one cause of the significant differences in the SMRs of lung cancer between males and females is probably due to the fact that $80 \%$ of smokers in Japan are males. Another likely cause is that most of the male subjects worked outside of residential areas. It has also been reported that "A difference in sensitivity to toxic 
chemical substances is an important and difficult issue in assessing health risk. Sensitivity factors can be regarded as age, gender difference, and history of disorders, but that it is genetically controlled is also known [37]." Therefore, further investigation and study are called for to elucidate the effect of gender difference and other factors.

The results of this analysis verify that $\mathrm{SO}_{2}, \mathrm{NO}_{2}$ and SPM, which are found among air-polluting substances, do not affect the correlation between arsenic concentrations and the respective SMRs. However, heavy-metal positioning was observed in carcinogenic rating group 1 according to International Agency for Research on Cancer, which included nickel and hexavalent chromium in its analyses [38]. We therefore believe that further investigations on the relationship between these hazardous air pollutants and the SMR of lung cancer is called for.

In conclusion, our statistical analysis indicates that the SMR of lung cancer is significantly high in areas with arsenic concentrations of $1.77 \mathrm{ng} / \mathrm{m}^{3}$ or more.

Acknowledgments We are grateful to Dr. Junichi Misumi (Professors Emeritus of Oita University Faculty of Medicine) for his advice. We would also like to express our gratitude to the Statistical Library of Ministry of Internal Affairs and Communications, Statistical Consultation Division of the Ministry of Health, Labour and Welfare Secretariat Statistics and Information Department Planning Section, and the Oita Prefectural Institute of Health and Environment, which greatly assisted in the collection of the statistical data and information.

\section{References}

1. Oita Prefecture Agency. Quality of the environment in Oita (in Japanese). Oita: Oita Prefecture Agency; FY1974-FY1993, FY1999-FY2003.

2. Maeda I, Tanoue H, Ueki A, Nakagiri M, Kadota M. The study concerning the local characteristic of hazardous air pollutants in Okayama prefecture (in Japanese). Okayama Prefectural Inst Environ Sci Public Health. 2003;27:1-12.

3. UNEP/ILO/WHO. International Programme on Chemical Safety. Environmental health criteria \#18 (Arsenic). Geneva: UNEP/ILO/ WHO; 1981.

4. Ministry of the Environment. The carcinogenic evaluation and the environmental quality standards for air pollution concerning the monitoring materials - air quality. Tokyo: Ministry of the Environment; 1998. Available at: (http://www.env.go.jp/air/osen/ mon_h10/ref.html\#ref2).

5. Korte N. Naturally occurring arsenic in groundwaters of the Midwestern United States. Environ Geol Waters Sci. 1991;18: 137-41.

6. Chien-Jen C, Li-Ju L. Human carcinogenicity and atherogenicity induced by chronic exposure to inorganic arsenic. Adv Environ Sci Technol. 1994;27:109-31.

7. Abernathy CO, Thomas DJ, Calderon RL. Health effects and risk assessment of arsenic. J Nutr. 2003;133:1536-8.

8. Anetor JI, Wanibuchi H, Fukushima S. Arsenic exposure and its health effects and risk of cancer in developing countries: micronutrients as host defense. Asian Pac J Cancer Prev. 2007;8:13-23.
9. Eisler R. A review of arsenic hazard to plants and animals with emphasis on fishery and wildlife resources. Environ Sci Technol. 1994;127:185-259.

10. Dunn JE Jr, Linden G, Breslow L. Lung cancer mortality experience of men in certain occupations in California. J Public Health. 1960;10:1475-87.

11. Zheng T, Holford TR, Boyle P, Chen Y, Ward BA, Flannery J, et al. Time trend and the age-period-cohort effect on the incidence of histologic types of lung cancer in Connecticut, 1960 1989. Cancer. 1994;74:1556-67.

12. Zang EA, Wynder EL. Differences in lung cancer risk between men and women. J Natl Cancer Inst. 1996;88:183-92.

13. Boyle P. Cancer, cigarette smoking and premature death in Europe. Lung Cancer. 1997;17:1-60.

14. Ames BN, Gold LS. The prevention of cancer. Drug Metab Rev. 1998;30:201-23.

15. Anthonisen NR, Skeans MA, Wise RA, Manfreda J, Kanner RE, Connett JE. The effects of a smoking cessation intervention on 14.5-year mortality. Ann Intern Med. 2005;142:233-9.

16. Study committee report concerning smoking and health matter. Smoking and health (in Japanese). Tokyo: Hokendojinsya; 2002. pp 112-3.

17. Ministry of the Environment. Monitoring results of hazardous air pollutants (in Japanese). Tokyo: Ministry of the Environment; FY1999-FY2003.

18. Ministry of Health, Labour and Welfare. National Health Maps by Municipality. Tokyo: Ministry of Health, Labour and Welfare; FY1995-FY1999. Available at: http://graph-sys.health-net.or.jp/ ken-map/index.html.

19. Statistics and Information Department of the Ministry of Health, Labour and Welfare. Vital statistics of Japan (in Japanese). Tokyo: Ministry of Health, Labour and Welfare; FY1995FY1999.

20. Statistics Bureau of the Ministry of Internal Affairs and Communications. National census results (in Japanese). Tokyo: Ministry of Internal Affairs and Communications; 1995, 2000.

21. National Institute for Environmental Studies. Monthly and Annual Data on Environmental Air Values. Tokyo: National Institute for Environmental Studies; FY1999-FY2003. Available at: http://www.nies.go.jp/igreen/index.html.

22. Ministry of Internal Affairs and Communications. Municipal Settlement Situation Surveys (in Japanese). Tokyo: Ministry of Internal Affairs and Communications; FY1999-FY2003.

23. Nakamura Y. Deviation and cross (in Japanese). Public Health. 2001;65:124-9.

24. Kon N, Kon T. Investigation results of suspended particulate matter in the air (\#2) (in Japanese). Rep Aomori Prefectural Office Pollut Invest. 1985;7:43-7.

25. Kon N, Kon T, Nishizawa M, Izumi S. Investigation results of suspended particulate matter in the air (\#3) (in Japanese). Rep Aomori Prefectural Office Pollut Invest. 1986;8:47-55.

26. Sano M, Ohno T, Ito S, Ohtsuka S, Narumiya H. Survey of dust and metals in the ambient atmosphere (1985) (in Japanese). Rep Shiga Prefectural Inst Public Health Environ Sci. 1986;21:179-90.

27. Narumiya H, Ohno T, Ohtsuka S, Tanaka M, Kuroki S. Survey of suspended particulate matter, metals in the ambient atmosphere (1986-1988) (in Japanese). Rep Shiga Prefectural Inst Public Health Environ Sci. 1989;24:100-9.

28. Oita City Agency. Quality of the environment in Oita City (in Japanese). Oita: Oita City Agency; FY1985-FY1993.

29. Ministry of the Environment. Environmental quality standards in Japan - air quality. Tokyo, Japan: Ministry of the Environment; 2004. Available at: http://www.env.go.jp/en/air/aq/aq.html.

30. Gehring U, Cyrys J, Sedlmeir G, Brunekreef B, Bellander T, Fischer $\mathrm{P}$, et al. Traffic-related air pollution and respiratory health during the first 2 years of life. Eur Respir J. 2002;19:690-8. 
31. Ministry of the Environment. Air pollution report (FY2003) (in Japanese). Tokyo: Ministry of the Environment; 2004.

32. Furukawa T, Tango T. Statistics to medicine (in Japanese). Tokyo: Asakura Publ.; 1999. pp. 142-4.

33. Nakamura Y. Analyses essential for epidemiology (in Japanese). Public Health. 2001;65:741-5.

34. Schoenberg BS. Calculating confidence intervals for rates and rations. Neuroepidemiology. 1983;2:257-65.

35. Ministry of the Environment. Quality of the environment in Japan (in Japanese). Tokyo: Ministry of the Environment; 1987. pp. 7-11.
36. Ministry of Health and Welfare. National survey on smoking and health (in Japanese). Tokyo: Ministry of Health, Labour and Welfare; 1999.

37. Hirano S. The study concerning the revelation index for the harmful chemical substance and a sensitivity factor (in Japanese). Natl Inst Environ Stud News. 2003;21:5-7.

38. Grimsrud TK, Berge SR, Haldorsen T, Andersen A. Can lung cancer risk among nickel refinery workers be explained by occupational exposures other than nickel? Epidemiology. 2005;16:146-54. 